\title{
Towards Model Integrations of Tools and Techniques for Project Management Success
}

\author{
Tomas U. Ganiron Jr \\ International Economic Development and Research Center, Hongkong \\ College of Architecture, Qassim University, Buraidah City \\ tomasuganironjr@gmail.com
}

\begin{abstract}
Since the cost of construction materials and real estate value are increasing, the design and construction of buildings and infrastructures need to be more competitive by utilizing advanced tools and techniques for project management success. The methodologies of modern project management are highly analytical, usually requiring automated tools to support them on large projects. Managers prefer specific project methodology, while resist and face difficulties for an opportunity to manage another project with different methodology as they do not know how much commonality exists between the preferred and the new required methodology. This paper presents the different tools and techniques in engineering projects. The result was obtained from the views different client organizations, project managers, design consultants and contractors, as to what determines project success.
\end{abstract}

Keywords: Management, management success, organization, project management, project success

\section{Introduction}

As years goes by, the scope project management expanded in different kinds of various methodologies. These were developed to formalize the way organizations managed their projects. The expansion of methodologies' grew rapidly from the beginning of the 1970s into the 1980s [1, 12]. However, since the turn of the century, the focus seems to have shifted from organizations buying expensive methodologies from commercial vendors towards adopting the use of maturity models.

An industrial project, big or small, must be managed effectively to ensure the project's objectives are met. Project managers must be aware of their roles and responsibilities and fully understand how to use the tools that are available to monitor and assess the performance of the project. There is a wide range of project management tools and software available and in some cases project managers or team members might decide to develop their own. The role of a project manager is extremely important to the success of any project. For example, in larger projects, being able to work effectively with others and lead a team of project members is essential. Using tools and techniques to identify critical activities, giving those activities higher priority, and allocating adequate and appropriate resources to them, is vital to ensure a successful and timely project.

Today, project management has emerged as its own field, supported by bodies of knowledge and researches across many discipline. Although still relatively new, the field of software engineering has its own bodies of knowledge that include various methodologies, frameworks, tools and techniques supported by a continuous growing base of research. 


\section{Scientific Management}

Scientific management implies the application of science to the job management of an industrial concern [2]. It aims at replacement of traditional techniques by scientific techniques. Scientific management is a thoughtful, organized human approach to the job of management as contrasted with hit or miss, rule of thumb. It is the art of knowing exactly what you want men to do and then seeing that they do it in the best and cheapest way.

Scientific management includes finding the most efficient methods of production, scientific selection and training of worker, proper allotment of duties and work and achieving cooperation between workers and management.

The objectives or aims of scientific management may be summarized as shown in Figure 1.
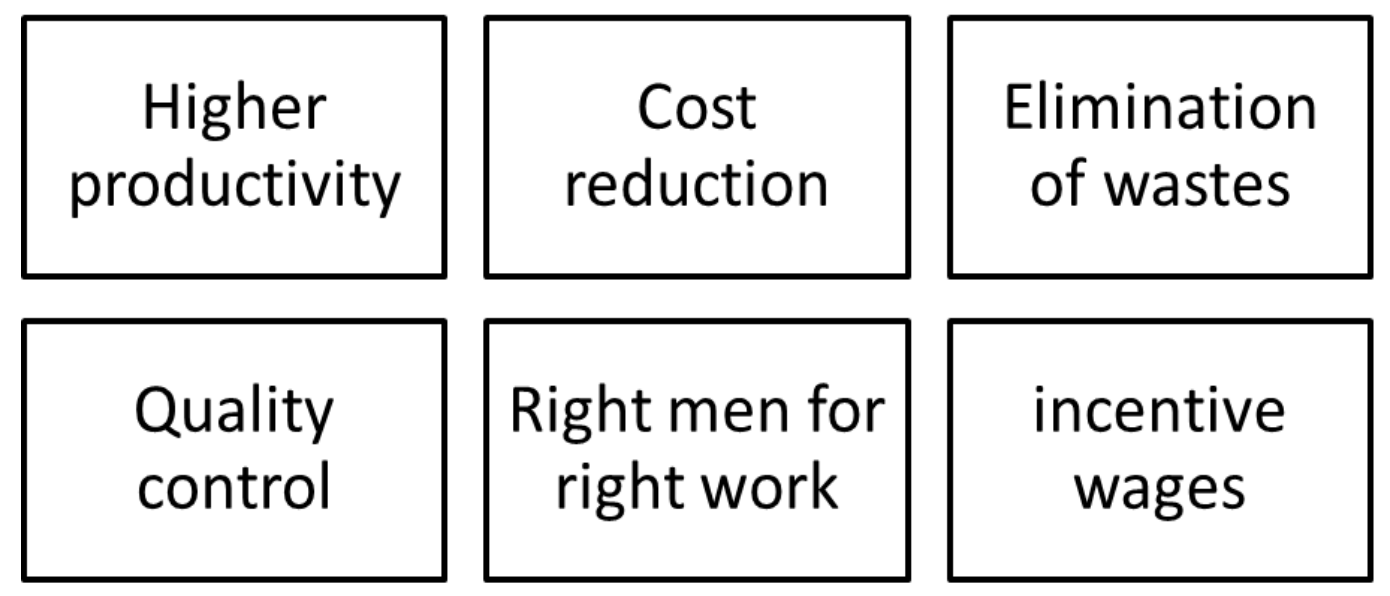

Figure 1. Aims of Scientific Management

With the use of scientific management, history proven that engineers were effective executives. This is due to their inherent analytical mind, creativeness, conceptual, and mathematical perceptions as they jumping in rendering effective decisions. By nature, engineers are not talker, just doers. As effective executive, engineers do not make many decisions because a decision on principle does not as a rule take longer than a decision on symptoms and expediency.

As an effective executive, engineers do not need to make many decisions because he solves generic situations through a rule and policy. They can handle most events as cases under the rule and that is by adaptation.

Engineers as executives are not paid for doing things they take to do. They are paid for getting the right things done and most of all in their specific tasks, that is, the making of right decisions.

Over the many years since scientific management was introduced, specialization has certainly raised efficiency and productivity, although in some other ways it has also created problems. However, in recent years, it has been proven that better technology alone cannot produce all the needed solutions. More reliance must be placed on people.

\section{Humanistic Management}

Humanistic management is an approach to management theory based on the idea of human needs and human values [3]. Employees are seen not merely as economic assets valued primarily for their productivity but as people with complex needs and a desire for meaningful and varied daily tasks. Implementing humanistic management concepts is 
difficult due to the complexity of human behavior and of ethical questions in general, and it has many challenges.

Humanistic management theories were developed in the 20th century in reaction to earlier theories of scientific management that emphasized productivity and profit above all other concerns. According to the Humanistic Management Center, an approach to management must include three key dimensions to be considered humanistic. This is shown in Figure 2. The first is a respect for the basic dignity and humanity of employees, customers and anyone else affected by the company's actions. The second is that all business decisions must include thoughtful ethical analysis. The third is that business decisions should be made in dialogue with all those who will be affected by them.

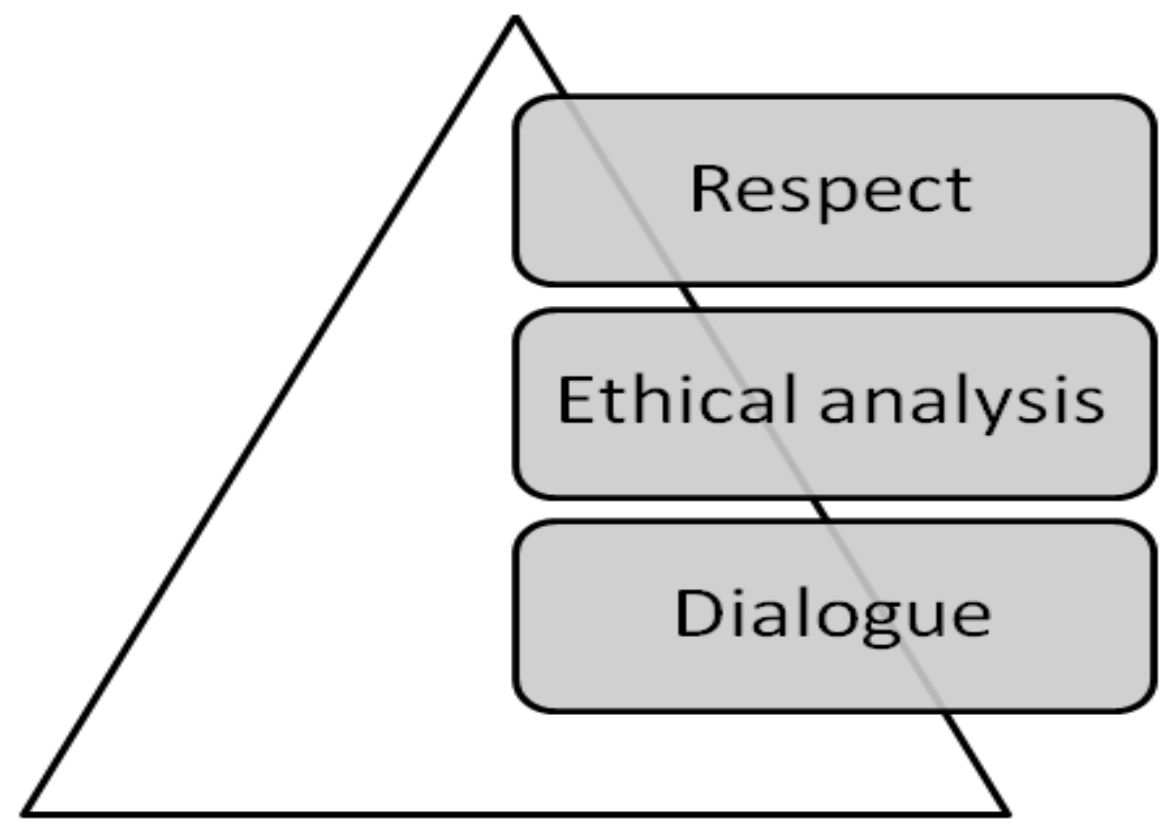

Figure 2. Three Dimensions of Humanistic Management

Respect for the inherent dignity of employees is one of the defining characteristics of humanistic management. This respect is conveyed through the reorganization of the company's management structure and processes to give workers the highest level of autonomy and control over their own work possible. One challenge of this approach is that it can seem to be aimed at enhancing employee job satisfaction when the real goal is to improve productivity. If employees believe that new processes and structures are really intended to manipulate them, they will respond with resentment or passive resistance. Business owners wishing to implement humanistic principles cannot do so with an ulterior motive. Employees will only respond positively to this management style if the company owners genuinely concern themselves with employee well-being.

\section{Risk Management}

In a project environment, there is always a risk or chance that adverse conditions occur, which cause the project to fail or fail to meet its planned objectives, for instance the time, cost and quality. A project manager or a project board should consider the different tasks, activities and work to accomplish project deliverables, and consider any risk that an actual outcome could differ to an expected outcome. The financial and non-financial aspects of each risk should be well documented. Each risk perhaps classified into groups for better understanding of its implications. 
Models such as PEST or SLEPT analysis and other derivatives help to analyze different types of risk [4]. Risk management processes can also help to identify that is controllable and uncontrollable, once each risk has been identified and the scale or impact of each clearly understood, appropriate risk management strategies can be implemented in order to control each risk. This will be an on-going activity throughout the various stages of

Applying a practical risk management process to the projects with the selfdiscipline and commitment to follow the process rigorously will underpin the chances of a successful outcome.

A simple way of looking at a generic Project Risk Management process, is to split it into 4 key activities shown in Figure 3.

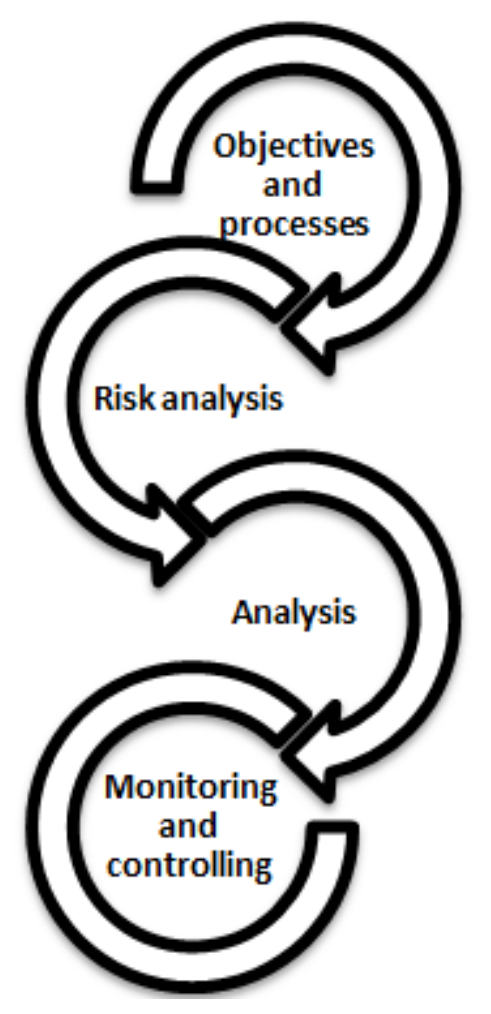

Figure 3. Risk Management Processes

In Figure 3, firstly, the objectives for the project risk management process to be used and align them with the overall objectives for undertaking the project - the criteria for success. Risk Registers are practical ways for logging identified risks so they may be managed effectively through the project risk management process.

Secondly, identify foreseeable risks and seek to understand the type of risk. For all risks identified, understand the likelihood and impact as well as any cause and effect relationships between risks.

Third, formulate methods and actions to reduce or eliminate identified risks in a structured and manageable way to enable continuous control of risk and uncertainty. Specific response actions may include the transfer, mitigation, allocation or acceptance of identified risks.

Lastly, throughout the whole project life-cycle, the level of risk facing the project should be measured in some way, as well as a measuring the effectiveness in responding to identified risks. 


\section{Quality Management}

Quality management is focused not only on product and service quality, but also on the means to achieve it. Quality management, therefore, uses quality assurance and control of processes as well as products to achieve more consistent quality. One technique that is used for quality management is six sigma.

Six Sigma is a business performance improvement strategy that aims to reduce the number of mistakes/defects to as low as 3.4 occasions per million opportunities. Sigma is a measure of "variation about the average" in a process which could be in manufacturing or service industry [5]. Six Sigma improvement drive is the latest and most effective technique in the quality engineering and management spectrum. It enables organizations to make substantial improvements in their bottom line by designing and monitoring everyday business activities in ways which minimizes all types of wastes and NVA activities and maximizes customer satisfaction. While all the quality improvement drives are useful in their own ways, they often fail to make breakthrough improvements in bottom line and quality. Six Sigma blends correct management, financial and methodological elements to make improvement in process and products in ways that surpass other approaches.

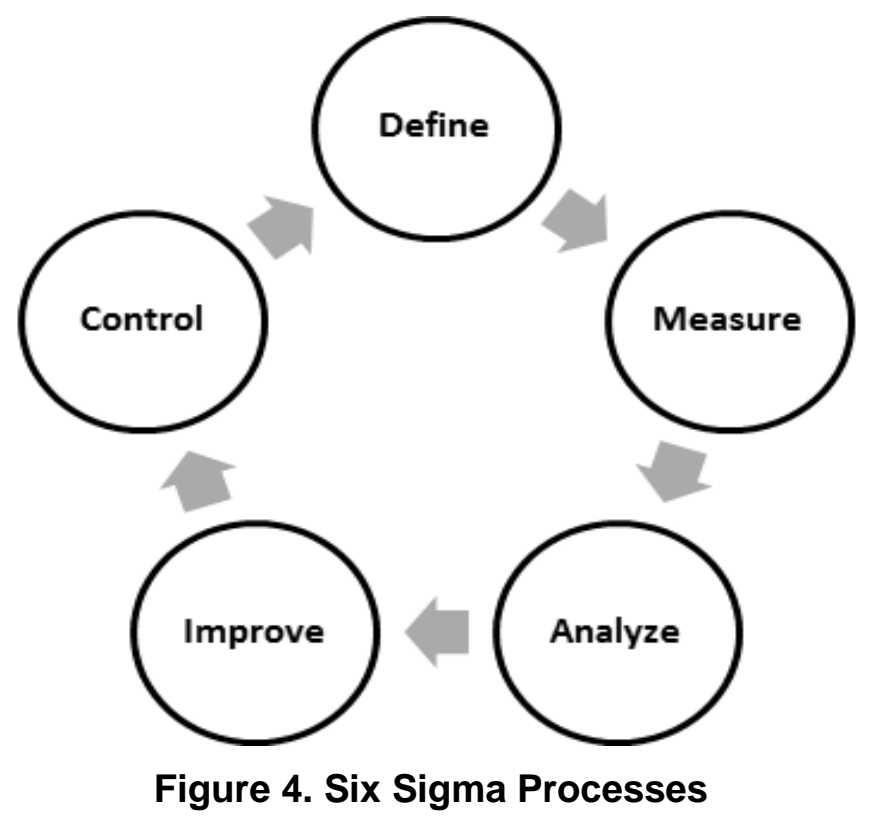

The methodology of Six Sigma basics in essence creates improvements by managing variation and reducing deficits in the processes of an enterprise. The first acronym stands for define, measure, analyze, improve, and control. These five elements focus on significant process improvements shown in Figure 4

Managing a business in any industry is especially difficult to keep up with on various levels. People usually find that they are unable to balance their obligation to a productive and proficient operating model while still ensuring they have access to as much growth and profitability as possible. Anyone considering a Lean Six Sigma effort should know the basics of successfully implementing these management principles as part of making sure their efforts are well coordinated.

Lean Six Sigma management practices are designed to help businesses implement the most productive and failure proof operations possible throughout their organization. Companies are often interested in this particular model when attempting to ensure their efficiency levels and overall cost control needs are as 
carefully managed as possible at all times. Businesses considering the implementation of this model are quite specific in their efforts.

Any company that is considering lean concepts is faced with a wealth of opportunities for success. Many leaders are uncertain of where to even initiate their first steps while being assured their needs are fully met. Concentrating on numerous factors is actually quite helpful in making sure the program is as well managed as possible.

Leaders should initially be certain they fully comprehend all the principles and guidelines that are associated with this management practice through proper training for both themselves and their employees. The various guidelines and principles that govern this process are based on the need to be assured that all phases of implementation are accurate and appropriate for their organization. Specific training courses and certifications are readily available for leaders to participate in that are actively considering this particular option.

Another source of consideration in this effort is concentrating on the use of specifically trained consultants. Hiring a consultant is often a beneficial idea when implementing any kind of quality control program as they are typically versed in highly specialized forms of operations that are helpful to companies. Many professionals only charge a fee for their services if they are effective in providing guidance to their clients.

Companies should also make sure their employees are fully trained on all principles that are being discussed and considered. People often discover that employees are typically uncertain of what should be focused on throughout their daily routines when attempting to assist in implementing a lean strategy. Proper training and clear delegation of responsibilities helps ensure that everyone is on board with what is required of them..

\section{Change Management}

A change management strategy is a systematic approach to make adjustments for the application of a set of tools, processes or skills during a project or initiative $[6,7]$.

The employee does not have a responsibility to manage change - the employee's responsibility is no other than to do their best, which is different for every person and depends on a wide variety of factors (health, maturity, stability, experience, personality, motivation, etc.,). Responsibility for managing change is with management and executives of the organization - they must manage the change in a way that employees can cope with it. The manager has a responsibility to facilitate and enable change, and all that is implied within that statement, especially to understand the situation from an objective standpoint (to 'step back', and be nonjudgmental), and then to help people understand reasons, aims, and ways of responding positively according to employees' own situations and capabilities. Increasingly the manager's role is to interpret, communicate and enable - not to instruct and impose, which nobody really responds to well.

Be wary of expressions like 'mindset change', and 'changing people's mindsets' or 'changing attitudes', because these languages often indicate a tendency towards imposed or enforced change and it implies strongly that the organization believes that its people currently have the 'wrong' mindset, which is never, ever, the case. If people are not approaching their tasks or the organization effectively, then the organization has the wrong mindset, not the people. Change such as new structures, policies, targets, acquisitions, disposals, re-locations, etc., all create new systems and environments, which need to be explained to people as early as possible, so that people's involvement in validating and refining the changes themselves can be obtained. 
Whenever an organization imposes new things on people, there will be difficulties. Participation, involvement and open, early, full communication are the important factors.

Workshops are very useful processes to develop collective understanding, approaches, policies, methods, systems, ideas, etc. Staff surveys are a helpful way to repair damage and mistrust among staff - provided they allow people to complete them anonymously, and provided you publish and act on the findings.

Management training, empathy and facilitative capability are priority areas managers are crucial to the change process - they must enable and facilitate, not merely convey and implement policy from above, which does not work.

Managers cannot impose change - people and teams need to be empowered to find their own solutions and responses, with facilitation and support from managers, and tolerance and compassion from the leaders and executives. Management and leadership style and behavior are more important than clever process and policy. Employees need to be able to trust the organization.

The leader must agree and work with these ideas, or change is likely to be very painful, and the best people will be lost in the process.

In business, a change management strategy describes specific ways in which an organization will address such things as changes in the supply chain, inventory requirements, scheduling or project scope. The goal of establishing a formal strategy is to ensure that any negative effects of change will be minimized. To effectively institute a change management strategy, stakeholders must create a plan for how to recognize when a change is need, how to approve changes, how to implement changes and how to monitor changes to ensure they have brought about the desired effect.

\subsection{Freeze Change Model}

As shown in Figure 5, the freeze change model recognizes that people like the safety, comfort and feeling of control within their environment. It also recognizes that they derive a strong sense of identity from their environment

Thus change is threatening to that status quo and causes discomfort. This usually requires some form of intervention to get them moving such as a restructuring, or the creation of some form of real crisis - or the perception of a real crisis!

Another common strategy is to present the "cold hard logic" of "irrefutable facts" that make change inevitable - basically, any form of intervention that is designed to destabilize people and render them susceptible to change.

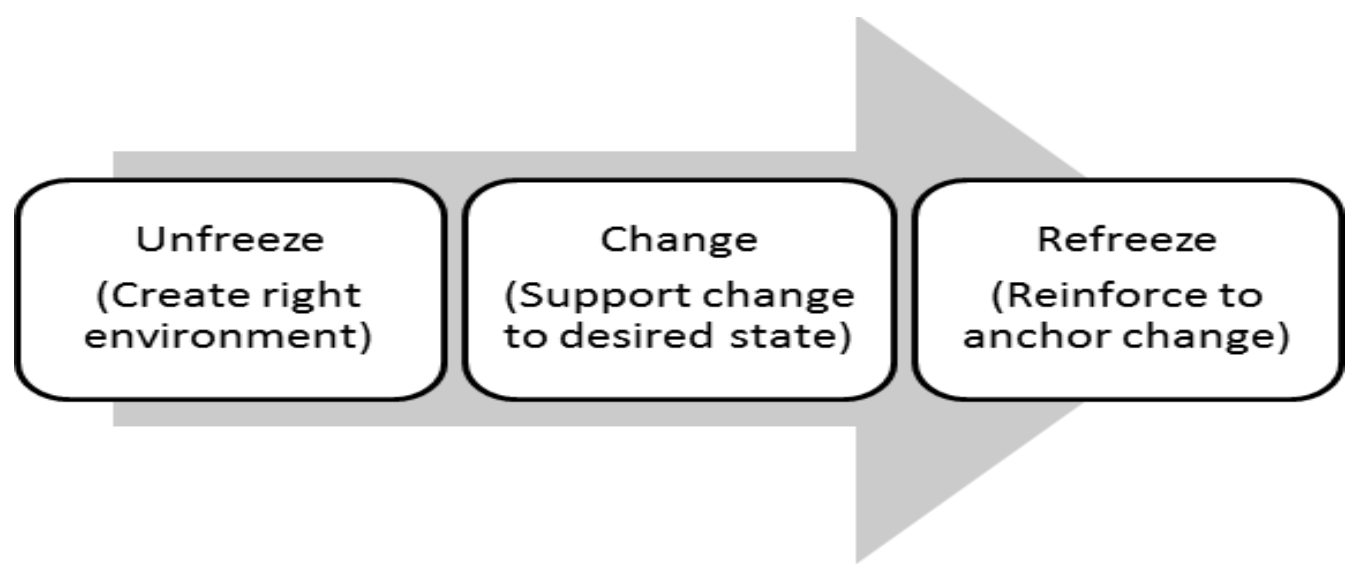

Figure 5. Freeze Change Model 
A key part of the freeze model is the idea that change, even at the psychological level, is a journey rather than a simple step. This journey may not be that simple and the person may need to go through several stages of misunderstanding before they get to the other side.

It is painfully clear that managing the transition requires time and sensitive skillful leadership - exercised within people-focused change management processes.

The work of William Bridges focuses specifically on the transitions and the psychological changes that lie behind significant organizational change.

Bridges maintains that situational changes are not as difficult for companies to make as the psychological transitions of the people impacted by the change.

\subsection{Kubler-Ross Model}

The Kübler-Ross model, or the five stages of grief, is a series of emotional stages experienced by survivors of an intimate's death, wherein the five stages are denial, anger, bargaining, depression and acceptance $[8,9]$.

The model was first introduced by Swiss Psychiatrist Elisabeth Kübler-Ross in her 1969 book, On Death and Dying, and was inspired by her work with terminally ill patients [10]. Motivated by the lack of curriculum in medical schools on the subject of death and dying, Kübler-Ross examined death and those faced with it at the University of Chicago's medical school. Kübler-Ross' project evolved into a series of seminars which, along with patient interviews and previous research, became the foundation for her book. Since the publication of "On Death and Dying", the Kübler-Ross model has become accepted by the general public; but, its validity is not yet consistently supported by the majority of research.

Elisabeth Kübler-Ross noted that the stages are not a complete list of all possible emotions, and can occur in any order, and that not everyone who experiences a lifethreatening or life-altering event feels all five of the responses. The stages, popularly known by the acronym DABDA, include:

7.2.1. Denial: This is usually a temporary initial response along the lines of: "I feel fine... this can't be happening to me.

7.2.2. Anger: Once the realization that that denial cannot continue then anger sets in: "Why me? It's not fair!"; Who is to blame?".

7.2.3. Bargaining: This stage involves the hope that the individual can somehow postpone or delay the inevitable... "Just give me a bit longer... just let me finish.... “

7.2.4. Depression: During this fourth stage, the person begins to understand the certainty of what is going to happen:" What's the point? I can't go on?"

7.2.5. Acceptance: This final stage comes with a measure of peace and acceptance of the inevitable. "It's going to be okay... can't fight it, I may as well prepare for it." 


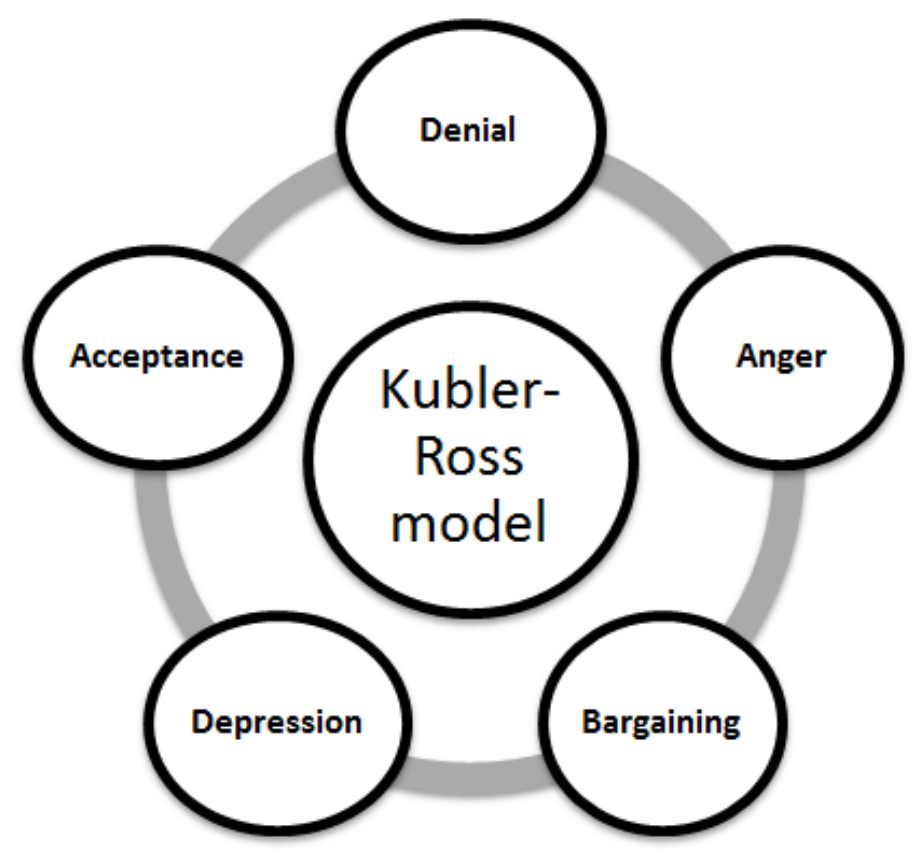

Figure 6. Kubler-Ross Model

As stated above shown in Figure 6 ,these stages do not necessarily come in order, nor are all stages experienced by all patients. She stated, however, that a person always experiences at least two of the stages. Often, people experience several stages in a "roller coaster" effect-switching between two or more stages, returning to one or more several times before working through it. Women are more likely than men to experience all five stages.

However, the Kübler-Ross hypothesis holds that there are individuals who struggle with death until the end. Some psychologists believe that the harder a person fights death, the more likely they will be to stay in the denial stage. If this is the case, it is possible the ill person will have more difficulty dying in a dignified way. Other psychologists state that not confronting death until the end is adaptive for some people.

\section{Project Cost Management (PCM)}

This is a method that uses technology to measure cost and productivity through the full life cycle of enterprise level projects. PCM encompasses several specific functions of project management including estimating, job controls, field data collection, scheduling, accounting and design.

Beginning with estimating, a vital tool in PCM, actual historical data is used to accurately plan all aspects of the project. As the project continues, job control uses data from the estimate with the information reported from the field to measure the cost and production in the project. From project initiation to completion, project cost management has an objective to simplify and cheapen the project experience.

This technological approach has been a big challenger to the mainstream estimating software and project management industries. Organizations that deliver Project Cost Management software include ARES Prism, EcoSys, Hard Dollar Corp, and Monitor manpower, as well as numerous others [11, 12].

Project Cost Management is one of the ten Knowledge Areas outlined in the A Guide to the Project Management Body of Knowledge (aka the PMBOK Guide). It is used during the Planning and Monitoring \& Controlling Process Groups. 
Among the many responsibilities and duties, project managers find themselves in charge of the correlation between the project, and the cost related to it.

The cost of a project is defined by the PMBOK as: "The resources necessary to complete scheduled activities." Thorough management of own project's cost will cover three main stages shown in Figure 7.

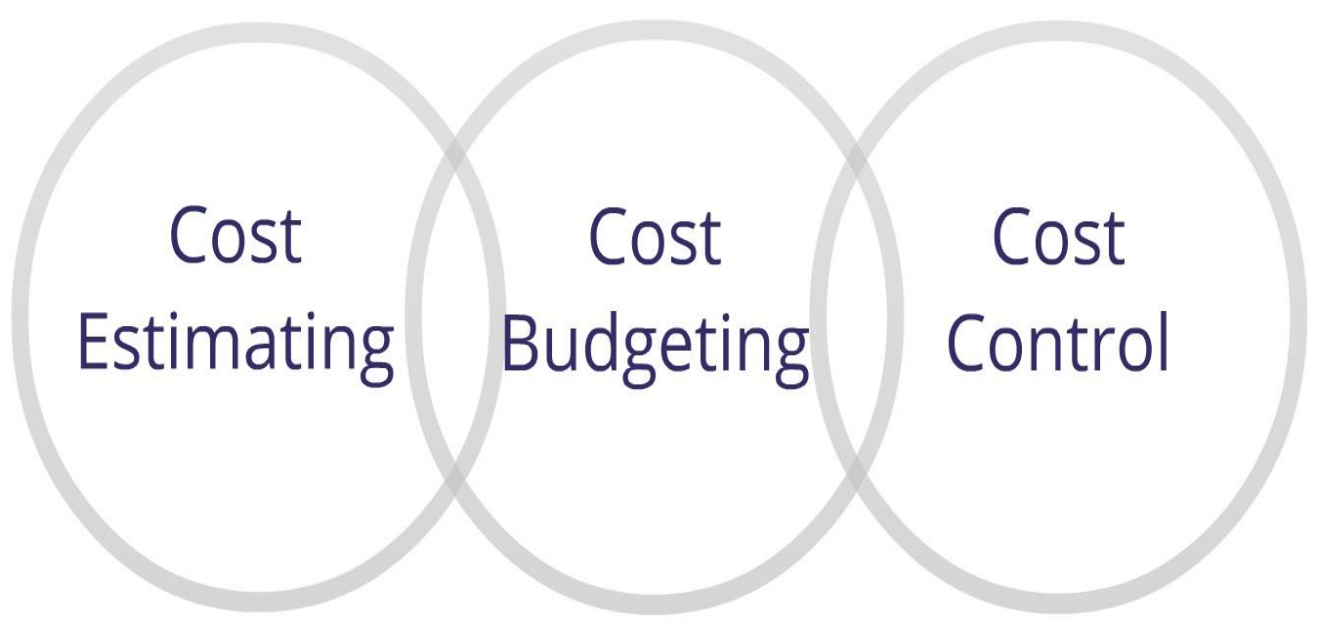

Figure 7. Three Main Stages of Project Cost Management

\subsection{Phase 1: Cost Estimating}

Cost estimating is a well formulated prediction of the probable cost of a particular project. In layman's terms, you're doing what you can in order to predict the total cost of a project in order to help make sense of the scope of your project and the frame of time that you'll be working within. In project management, the 'Project Triangle' shown in Figure 8 is a graphic which helps managers understand the relation between the project's main attributes. In deciding to focus on two of the features, the other will suffer.

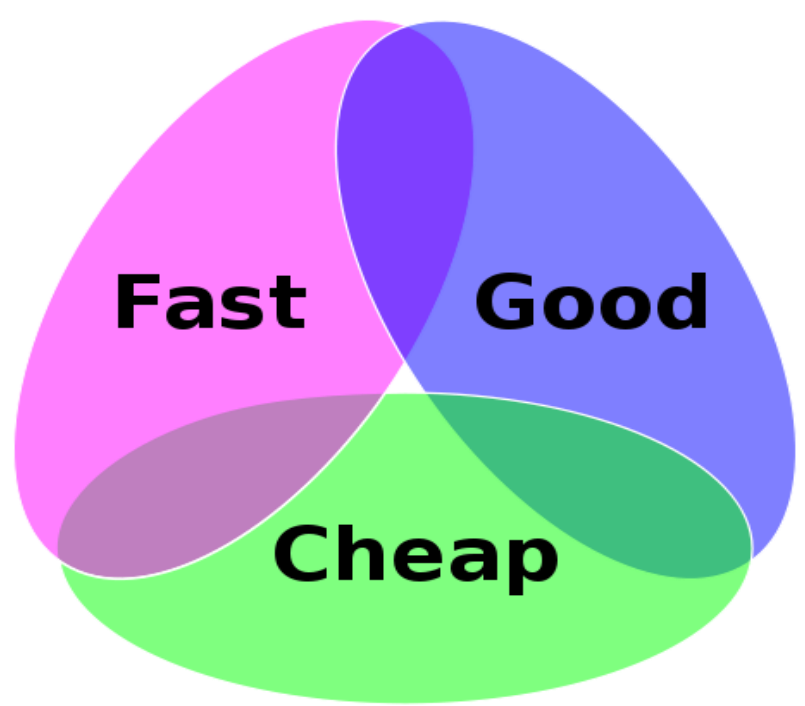

Figure 8. Project Triangle

More than a simple number, cost estimates are carefully determined for reference when breaking down required funding, and to gauge the needs for a project. A cost 
estimate should not be confused with a project budget. A project budget will include the total of the cost estimate and will also include plans for saving and borrowing.

A cost estimate can be classified as one of two different types: conceptual and detailed estimates. Each one can be broadly defined in the following way:

8.1.1. Conceptual: Also known as Parametric Estimating, Conceptual estimates include considering the historical data known for costs related to the project (for example: wages, materials, etc.,). Initially, these estimates are not thorough and are typically declared before there is any in-depth research done or context developed.

8.1.2. Detailed: A detailed cost estimate is the product of a process that breaks down the items of work in an orderly and logical way, determining the cost of each item through the use of cost estimating tools and techniques

8.1.3. Cost Estimating Tools and Techniques: There are many tools and techniques that one can use to establish the cost of their project while any combination of the tools will suffice, there is an easy way to cover every base [1315]. These are (a) Parametric estimating- These uses statistical information and historical data to combine with other variables in order to calculate a cost estimate. This technique can produce higher levels of accuracy depending on sophistication. This tool is often combined with Analogous Estimating in order to get a clear picture of the project cost based off of historical data. (b) Analogous Estimating This means using the actual cost of previous, similar projects as the basis for estimating the cost of the current project. (c) Analogous Estimating is used to estimate costs when there's a limited amount of detailed information available. Once historical data is collected, the project manager can seek more up-to-date information. (d) Determine resource cost rates-the person determining the cost must know the unit cost rates, such as staff costs per hour and bulk material cost. Gathering quotes is one way of obtaining rates. (e) Bottom-up estimating Typically motivated by the size and complexity of the individual schedule. The cost is usually estimated with the lowest level of detail and is then rolled-up to higher levels of reporting and tracking and, (f) Project management software - Cost estimating software applications or computerized spreadsheets, simulation and statistical tools simplify techniques and allow an entrepreneur to consider more variables.

\subsection{Phase 2: Cost Budgeting}

The process of creating a budget for the project is a simple, yet necessary phase in defining the total cost of a project. Essentially, cost budgeting establishes a parameter in which the project can be completed. Cost budgeting is the idea of using what we know about each one of those elements to put a fence around what the project manager decides is most important.

The budget, or 'fence' serves to show what lines to stay between, and to help everyone acknowledge what's on the inside and outside.

As a summary of cost estimates, the project cost budget is used to divide necessary costs and resources amongst their appropriate project needs shown in Figure 9. 


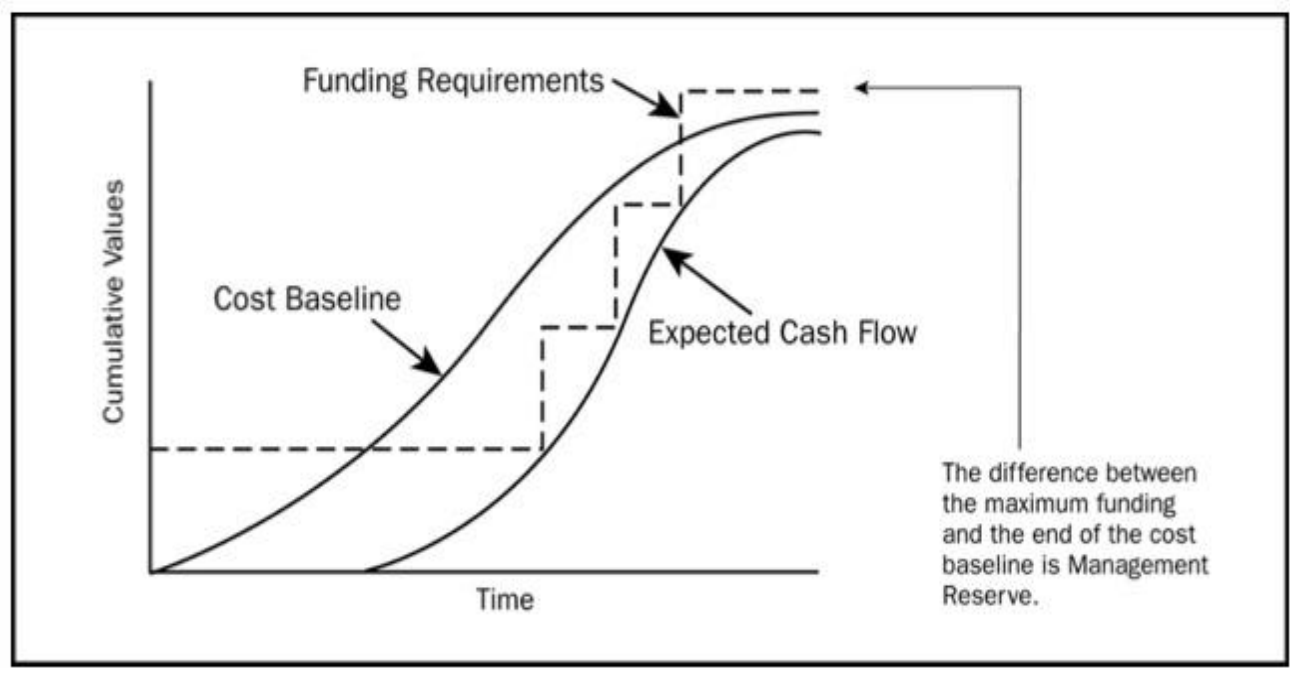

Figure 9. Project Management Body of Knowledge

There are four tools that the Project Management Body of Knowledge suggests as uses for creating a cost budget . They are as follows:

8.2.1. Cost Aggregation: Allowing each individual cost to accumulate, following the structure of the WBS. Cost Aggregation also calls for the distribution of payments with respect to the schedule base line.

8.2.2. Reserve Analysis: Management contingency reserves are budgets reserved for unplanned, but potentially required, changes to project scope and cost.

8.2.3. Parametric Estimating: Much like determining a cost estimate on a resource cost rate, parametric estimating relays on formulas created to achieve a budgets based off of the original budget of a small unit or process.

8.2.4. Funding Limit Reconciliation: Characterized by comparing and adjusting the funding limits and the estimated costs by refining the scope of the project, rescheduling activities, and tweaking various other details.

\subsection{Phase 3: Cost Control}

Project cost control is the final phase of project cost management and is an ongoing effort to ensure that decisions made within the first two stages are accurate and kept up-to-date in order to avoid risk. When it becomes necessary to deviate from an established cost, the estimate and budget must be taken into consideration in order to maintain appropriate capital for the project.

Entrepreneurs are most comfortable when they have the freedom to think on their feet and make decisions on the fly. The project management body of Knowledge supports its relevancy by giving founders the insight that they need to make calculated decisions and plan for the unexpected.

\section{Conclusions}

The most difficult parts in selecting project management tools and techniques are the methodologies. The criterion for choosing a methodology for any project is mainly based on an expert's opinion, past working experience, government rules and regulations, organization, senior management, stakeholder's preferences and client 
location. All of these can have positive or negative impact on the underdevelopment projects.

However, all of the above mentioned criterion have inbuilt quality of rigidness. None of these provide any opportunity to analyses the nature of project and then decide the future course of action related to the selection of project management methodology.

There are points where one methodology has some powerful tool and procedure than the others. Therefore in order to make the most of these established methodologies, a combine, mixed approach is required to get the best possible results.

\section{References}

[1] T. U. Ganiron Jr., S. Alyahya and A. M. Toumi, "Handouts in GE 402 Course (Project Management)", Qassim University, Buraidah City, (2013).

[2] S. Al-Freidi, "Unified Project Management Methodology", Ph.D. Thesis, Faculty of Engineering, Cairo University, Giza, (2013).

[3] R Sargean, "Creating Value in Project Management using PRINCE2", Queensland University of Technology, Queensland, (2010).

[4] J. Fisher, "Refreshing Management of Risk: Guidance for Practitioners" TSO and John Fisher,

[5] Unconfused, (2010).

[6] T. Ucol-Ganiron Jr. and T. Malvecino-Ganiron, "Managing Career Success of Geodetic Engineers", International Journal of Education and Learning, vol. 2, no. 1, (2013), pp. 13-24.

[7] "Comparing the Differences and Complementary features of PRINCE2 ${ }^{\circledR}$ and the PMI PMBOK®", Guide, ESI International, (2009).

[8] D. Rainey, "Inventing the Future Through Strategy, Innovation, and Leadership", American Scientific Publishers, Los Angeles, (2009).

[9] T. U. Ganiron Jr., L. Estiller, M. Aguirre, R. Bunag and R. Gallardo, "Technical Guidelines in the Design and Construction of Subdivision in Up-Land Area in Antipolo, Rizal", BS Thesis, Civil Engineering Department, FEATI University, Manila, (2003).

[10] S. Sahibudin, "Centre Combining ITIL, COBIT and ISO/IEC 27002 in Order to Design a Comprehensive IT Framework in Organizations", University of Teknol, Malaysia, (2010).

[11] T. U. Ganiron Jr., "The additive value of psychological capital in predicting structural project success and life satisfaction of structural engineers", International Journal of Social Science and Humanity, vol. 2, no. 4, (2012), pp. 291-294.

[12] "TOGAFTM 9 and ITIL ${ }^{\circledR}$ V3 Two Frameworks Whitepaper", Tom van Sante and Jeroen Ermers Consulting, (2009).

[13] "Strategy Deployment through Portfolio Management: A Risk-based Approach", Ernst \& Young Ltd., (2010).

[14] "Advanced Pipeline System", Onehunga, Auckland, (2009), Retrieved from http://www.advancedpipeline.com/.

[15] S. Millar, "Managing Organizations in New Zealand", Pearson Education, (2006).

[16] T. Ucol-Ganiron Jr. and T. Malvecino-Ganiron, "Social Capital on Civil Engineer Career Success", International Journal of Innovation, Management and Technology, vol. 3, no. 6, (2012), pp. 718-724.

[17] C. E. Larsen, R. Trip and C. R. Johnson, "Methods for procedures related to the electrophysiology of the heart", U.S. Patent 5,529,067, (1995) June 25.

\section{Author}

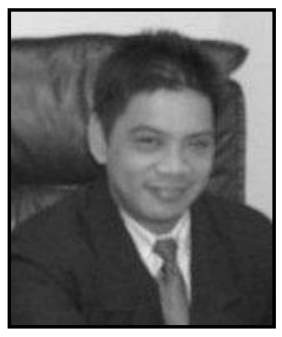

Tomas U. Ganiron Jr., obtained his Doctor of Philosophy in Construction Management at Adamson University (Philippines) in 2006, and subsequently earned his Master of Civil Engineering major in Highway and Transportation Engineering at Dela Salle UniversityManila (Philippines) in 1997 and received Bachelor of Science in Civil Engineering major in Structural Engineering at University of the East (Philippines) in 1990. He is a registered Civil Engineer in the Philippines and Professional Engineer in New Zealand. His main areas of research interest are construction engineering, construction management, project management and recycled waste materials. He has been the resource person in various seminars in New Zealand 
(like in Auckland University of Technology, University of Auckland and University of Canterbury). He was connected with Advanced Pipeline System in New Zealand as Construction Manager wherein he supervised the sewerage and waterworks projects. He was the former Department Head of Civil Engineering in FEATI University (Manila) and former Department Head of Physics in Emilio Aguinaldo College (Manila). He is also very active in other professional groups like Railway Technical Society of Australasia and Australian Institute of Geoscientists where he became committee of Scientific Research. He has received the Outstanding Civil Engineer in the field of Education given by the Philippine Media Association Inc. (1996), ASTM Award CA Hogentogler (2008) by IPENZ in New Zealand and Outstanding Researcher (2013) in Qassim University, Buraidah City. On the second week of February 2015, Dr. Ganiron Jr. was included in the Ranking of Scientists according to Google Scholar Citation public profile (http://www.webometrics.info/en/node/81). 